\title{
An Assessment of Malaria Parasite Density among HIV/AIDS-Subjects at Different Levels of CD4 T-Cells Prior to Antimalarial Therapy at Chulaimbo Sub-County Hospital, Western Kenya
}

\author{
J. K. Kirinyet $(\mathbb{D}$ \\ Department of Medical Microbiology \& Parasitology, School of Medicine, College of Health Sciences, Moi University, \\ P.O. Box 4606-30100, Eldoret, Kenya
}

Correspondence should be addressed to J. K. Kirinyet; joelkirinyet@gmail.com

Received 9 February 2019; Revised 2 May 2019; Accepted 23 May 2019; Published 1 July 2019

Guest Editor: Gabriel O. Dida

Copyright ( 2019 J. K. Kirinyet. This is an open access article distributed under the Creative Commons Attribution License, which permits unrestricted use, distribution, and reproduction in any medium, provided the original work is properly cited.

\begin{abstract}
Background. Malaria and HIV/AIDS infections are among the major public health concerns in sub-Saharan Africa, where they are associated with high morbidity and mortality. Recent findings indicate that individual people living with HIV/AIDS (PLWHA) with lower levels of CD4 T-cell count below $200 / \mathrm{mm}^{3}$ tend to experience higher mean malaria parasite densities than their counterparts with higher CD4 T-cells counts. Aim. The study was conducted to assess the pattern of malaria parasite density at different levels of CD4 T-cells among people living with HIV/AIDS in Western part of Kenya. Subjects and Methods. A randomized antimalarial treatment study among 126 people living with HIV/AIDS was conducted at Chulaimbo Sub-County Hospital, Western Kenya. All the participants enrolled into the study had their blood samples assessed for malaria parasite densities before commencement of antimalarial therapy and the results correlated with their CD4 T-cells levels obtained from their respective files. Results. Mean malaria parasite density on pretreatment samples was 43,168 parasites / $\mu \mathrm{L}$ of blood, median was 17,720 , and mode was 4,000 . Male participants had a higher geometrical mean parasite density $(26,424)$ compared to females' $(15,346)(p=0.03)$. Low CD4 counts were associated with high density malaria parasitaemia and consequently, very high CD4 counts seemed to exhibit low malaria parasite density among PLWHA. An insignificant negative correlation, however, between CD4 T-cells count and malaria parasite densities was noted $(\mathrm{p}=0.169)$. Conclusion. The study was able to establish higher parasite density among individuals with $\leq 200$ cells $/ \mu \mathrm{L}$ than their counterparts with $>200$ cells $/ \mu \mathrm{L}$ of CD4 T-cell levels in PLWHA resident in Western Kenya. Secondly, males significantly had a higher geometrical mean parasite density than females regardless of their CD4 status. It is anticipated that the results from this study could be used/applied in developing interventional measures to address malaria/HIV-AIDS coinfections aimed at saving life, particularly in the sub-Saharan African region where the two infections are rampant.
\end{abstract}

\section{Introduction}

In sub-Saharan African countries, HIV/AIDS and malaria coinfection are among the most important public health burden/concern evidently contributing to high morbidity and mortality in the region. Over the years, the prevalence, morbidity, and mortality associated with the two coinfections have been changing globally and the trend has been varying from one region to another. Globally, it was estimated that 212 million cases of malaria occurred in 2015, representing a $22 \%$ decline from the figures reported in the year 2000 and a further decline of $14 \%$ since 2010. The African and Asian regions/continents where $90 \%$ of world malaria cases were reported during the same period had experienced minimal disease decline by between 2 adn $7 \%$ [1].

In sub-Saharan Africa, malaria cases decreased from 146 million in 2005 to 114 million in 2015. However, high infection rates in children aged 2-10 have been widely reported, though mortality rates declined to $29 \%$ [1]. In Kenya, it is estimated that malaria episodes accounted for 6.7 million new clinical malaria cases and 4,000 deaths in 2015, especially among communities living in Western Kenya [2]. 
The pandemic of HIV/AIDS infection has persistently remained a major health concern since its discovery in the 1980s. Globally, people living with HIV/AIDS as of December 2015 were estimated at 36.7 million (all ages) with new infection (all ages) of 2.1 million. This represents an increase of $6.4 \%$ from 33 million in 2007 estimates [3] with 19 million from Eastern and South African regions. New infections reported in the two regions at the time were 960, 000 with about 1.1 million deaths. Kenya as a country ranks fourth-largest in HIV/AIDS epidemic in the world alongside Mozambique and Uganda with approximately 1.6 million people living with HIV by end of 2016 and an estimated 36,000 deaths due to AIDS-related illnesses [4]. Further, western part of the country is the most affected region in the country with highest rates of infection between $19.3 \%$ and $25.7 \%[5]$.

Malaria and HIV/AIDS overlapping geographical distribution has raised a lot of concerns and challenges in public health, with HIV infection increasing malaria susceptibility and reducing the efficacy of antimalarial drugs, while malaria infection has been found to increase the risk of HIV disease progression and mother-to-child transmission of HIV [6].

In endemic malaria areas of sub-Saharan Africa, HIV has been found to increase the risk of malaria infection especially in subjects with increased immunosuppression, while in unstable malaria areas, HIV-infected ones are at high risk of developing complicated and severe malaria that may result in death [7].

Malaria and HIV/AIDS coinfections are increasingly reported worldwide [8] and the interaction may lead to inadequately/poorly understood effect(s) on the disease(s) outcome and clinical presentation. In HIV/malaria coinfected patients, a significant variation in parasite density has been reported [9]. Interaction between malaria and HIV/AIDS infections and to some extent TB in areas where the three infections overlap has been reported to increase malaria parasitaemia levels, acid fast bacilli (AFB) count, and decreased Hgb levels [10]. In a study carried out among adults in Gabon, Central Africa, low CD4 T-cells counts $(<200$ cells $/ \mu \mathrm{L}$ ) in HIV positive subjects were associated with high parasite density levels [11]. Several studies on the association of the two infections in Western Kenya have been conducted in the past but no similar study has been done for the patients presenting at the Chulaimbo Sub-County Hospital under antimalarial directly observed therapy (DOT). The study was conducted to assess the pattern of malaria parasitaemia densities in different levels of CD4 T-cells among people living with HIV/AIDS in the surrounding areas within $10 \mathrm{~km}$ radius of the site. The findings will enable formulation of targeted interventions to address the coinfections in the region.

\section{Materials and Methods}

2.1. Study Area and Site. The study was conducted at Chulaimbo Health Centre, located some $24.1 \mathrm{~km}$ north of Kisumu City in Western part of Kenya (Figure 1). The study area is located at latitude: $0^{\circ} 06^{\prime} 07^{\prime \prime} \mathrm{S}$ and longitude: $34^{\circ} 45^{\prime} 42^{\prime \prime} \mathrm{E}$ with an elevation of $1174 \mathrm{~m}$ above sea level. It receives mean annual rainfall of $1800 \mathrm{~mm}$ with a mean annual temperature of 25 $35^{\circ} \mathrm{C}$.

2.2. Study Design and Setting. A prospective study was conducted at a health facility between November 2014 and October 2015 among people living with HIV/AIDS (PLWHA) in a malaria endemic zone within $10 \mathrm{~km}$ radius. Western Kenya, particularly the former Nyanza Province, is considered both malaria and HIV/AIDS endemic area $[2,5]$. According to Asito et al. (2011) [13], residents of Kisumu county (a malaria holoendemic region) receive between 100 and 300 infective mosquito bites per annum.

2.3. Patients' Eligibility and Enrollment. A total of 13,057 suspected malaria patients were screened at the facility and 5,867 had malaria. Of the positive malaria cases, 126 individuals with HIV/AIDS coinfection, aged between 2 and 72 years, met the inclusion criteria to participate in the study. They comprised both male and female subjects drawn from among those attending HIV management care within the health facility. Eligibility to the study was based on malaria positive slide with monoinfection of $P$. Falciparum; asexual parasitaemia of $\geq 1000$ and $\leq 200,000$ parasites $/ \mu \mathrm{L}$; febrile state with an auxiliary temperature of $\geq 37.5^{\circ} \mathrm{C}$; haemoglobin ( $\mathrm{Hb})$ of $\geq 5 \mathrm{~g} / \mathrm{dL}$ of blood and willing to give consent. Ineligibility to the study was based on multiple infections with Plasmodium species; aged below 2 years; severe anaemia ( $\mathrm{Hb}$ $\leq 5.0 \mathrm{~g} / \mathrm{dL}$ ); females with a positive pregnancy test; history of taking antimalarial drugs within 48 hours prior to visiting the health facility; severe opportunistic infections (OI) and recipient of second-line regimen of ARV treatment (Kaletra).

2.4. Sample Size Determination. The sample size required for this study was calculated based on $95 \%$ and $90 \%$ confidence levels and margin of error of $5 \%$ and $10 \%$, respectively, for the two drugs in accordance with Lemeshow et al. (1990) formula. The minimum sample size (n) was thus calculated as

$$
\mathrm{n}=\frac{2\left(\mathrm{Z}_{1-\propto / 2}+\mathrm{Z}_{1-\beta}\right)^{2} \delta^{2}}{\left(\mathrm{M} 1-\mathrm{M}_{2}\right)^{2}}
$$

where $\mathrm{n}$ is the minimum sample size, $\mathrm{Z}_{1-\propto / 2}$ is the standard error of first drug (Quinine) $=1.96(95 \%), Z_{1-\beta}$ is standard error of second drug $\left(\right.$ Coartem $\left.^{\circledR}\right)=1.282(90 \%), \delta$ is standard deviation of Quinine $(=12),[14], \mathrm{M}_{1}$ is mean parasite clearance of Quinine ( $41 \mathrm{hr}), \mathrm{M}_{2}$ is mean parasite clearance of Coartem $^{\circledR}(36 \mathrm{hr})$, and $\mathrm{n}=2(1.96+1.282)^{2} \times 12^{2} /(41-36)^{2}=121$ patients.

2.5. Sample Collection and Processing Procedures. Blood smears (both thick and thin) were collected from each participant on day zero (D0) prior to commencement of treatment. Thin blood smears were fixed using absolute methanol prestaining and both slides were stained with $10 \%$ buffered Giemsa stain ( $\mathrm{pH} 7.2$ ) for 10 minutes. Thin blood smears were examined for speciation while thick ones were quantitatively examined for parasitaemia from which parasite density was 


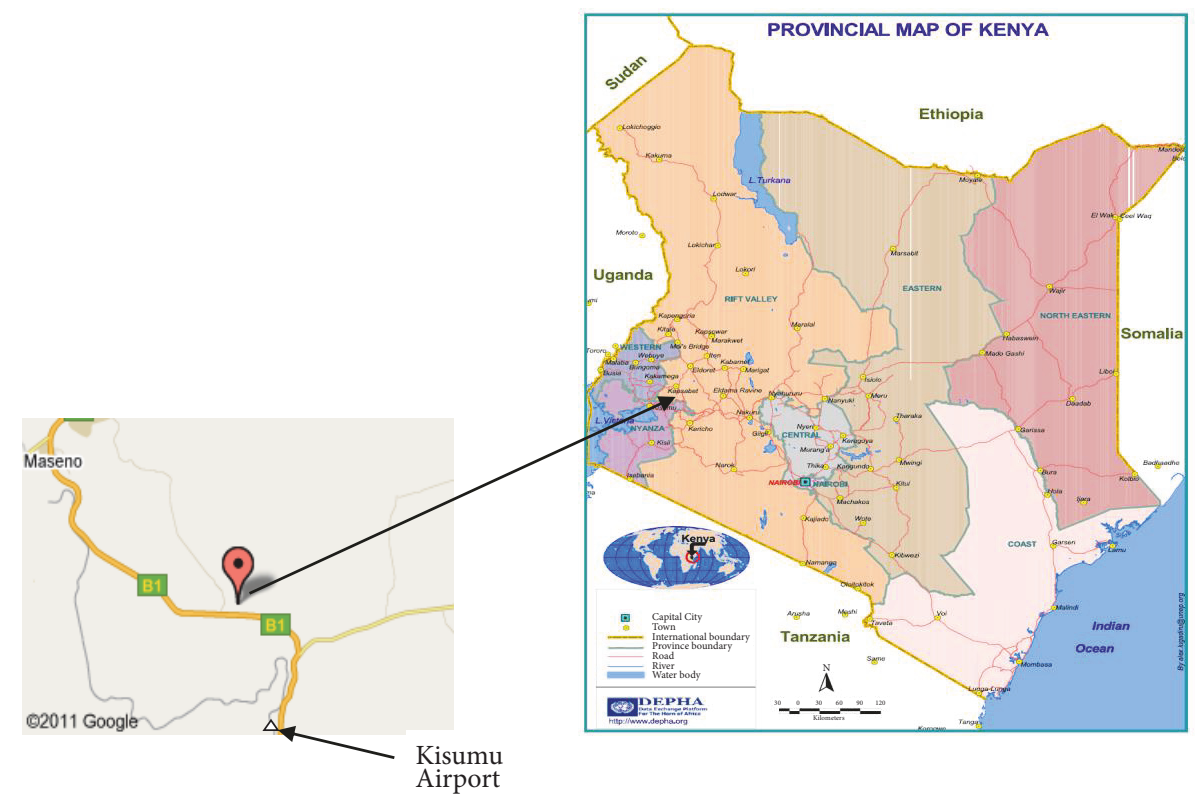

FIgure 1: Study area in Kisumu, Kenya. Source: The Data Platform for the Horn of Africa (DEPHA) (www.depha.org) [12].

calculated. Additional blood sample $(0.02 \mathrm{ml})$ was taken from the same prick for the estimation of haemoglobin $(\mathrm{Hb})$ using HemoCue AB, Angelhom, Sweden equipment.

Malaria parasites were counted in all positive thick blood smears and parasitaemia quantified per 200 white blood cells (WBC) counted in all fields. Ultimate parasitaemia value was calculated and given per microlitre $(\mu \mathrm{L})$ of blood using McKenzie et al. (2005) [15] mathematical formula:

Malaria parasites per $\mu \mathrm{L}$ blood

$$
=\frac{\text { No. malaria parasites counted } \times 8000}{200 \mathrm{WBC}}
$$

An average of 8000 leucocytes per $\mu \mathrm{L}$ blood (range $4000-11000 \mathrm{WBC} / \mu \mathrm{L}$ blood) was used as the standard for the study population.

Routine CD4 cells count was conducted among all the PLWHA attending the facility as part of management care and their data were available in individual files kept at the clinic.

2.6. Data Management and Analysis. Raw data was stored in Microsoft Excel Spreadsheet program and back-ups in flash discs and hand written copy in analysis notebook. After validation, data analysis was done using computer software SPSS (Statistical Package for Social Scientists) version 12 to generate means, standard deviation, median, and frequency distributions. To test for significant difference between groups, t-test was used for continuous variables such as age and parasitaemia that were normally distributed.

2.7. Ethical Approval. This study was granted approval by Institutional Research \& Ethical Committee (IREC) of Moi Teaching \& Referral Hospital /Moi University, School of Medicine, Eldoret-No: FAN: IREC 000421 and the Scientific Steering Committee (SSC)/National Ethical Research
Committee (NERC), KEMRI, Nairobi-No: SSC No 1495. All confidentiality regarding the study was professionally observed throughout the period of data collection. Access to participants' data at the study site was prohibited to persons other than the Principal Investigator. All participants to the study were assigned a study number at the point of recruitment to conceal their identity.

2.8. Quality Assurance. Both good laboratory and clinical practices were observed at study site by professionally qualified personnel through continuous monitoring by the Safety Monitor, Principal Investigator (PI), and the clinical consultant. Giemsa stain and chemicals such as methanol and buffer salts were sourced from Sigma-Aldrich (Catalogue No: 65637-25G; M1775-1GA; P3288-12VL, respectively). Training and quality assurance in microscopy for study site technologists was done continuously by the PI. All subjects' slides were taken to Malaria Unit, Centre for Biotechnological Research and Development, KEMRI, Nairobi, for reexamination and validation. Random microscopy checks of malaria slides were regularly done at the site by the PI for quality control.

\section{Results}

3.1. Demographic and Clinical Characteristics. A total of 126 participants were recruited into the study, 83.3\% (105/126) of which were adults while children participants were $16.7 \%$ (21/126). Mean age of the participants was 31.3 and median was 31 , the most frequent age was 30 years, and standard deviation was 14.7 in a range of between 2 and 72 years (Table 1).

The lowest recorded parasite density pretreatment among the participants was 1,000 parasites/ $\mu \mathrm{L}$ of blood while the highest recorded density was 199,000 parasites / $\mu \mathrm{L}$ of blood. 
TABLE 1: Profile of parasite density, temperature, Hb, and CD4 cells count of participants.

\begin{tabular}{lccccc}
\hline Parameter & Mean & Median & Mode & SD & Range \\
\hline Age & 31.3 & 31 & 30 & 14.7 & $2-72$ \\
Haemoglobin in g/dL & 11.7 & 11.9 & 12.5 & 2.25 & $5.3-17$ \\
Parasitaemia density per $\mu \mathrm{L}$ & 43168 & 17720 & 4,000 & 3602 & $1000-199000$ \\
Temp. in degrees Celsius & 37.6 & 37.4 & 47.0 & 1.34 & $34.8-40.9$ \\
CD4 per $\mu \mathrm{L}$ & 519.3 & 478 & & 296.3 & $12-1567$ \\
\hline
\end{tabular}

$\mathrm{Hb}$ : haemoglobin; SD: standard deviation; g/dl: grammes per decilitre; $\mu \mathrm{L}$ : microlitre.

TABLE 2: Geometrical means of age, parasite density, temperature, and $\mathrm{Hb}$ between gender day 0.

\begin{tabular}{lccc}
\hline Parameter & Male n-48 & Female n-78 & p-value \\
\hline Mean age & 30.2 & 32.1 & 0.524 NS \\
Gm parasitaemia & 26,424 & 15,346 & $0.03 \mathrm{~S}$ \\
Mean Hb & 12.4 & 11.2 & $0.04 \mathrm{~S}$ \\
Mean temperature in ${ }^{\circ} \mathrm{C}$ & 37.7 & 37.5 & $0.447 \mathrm{NS}$ \\
\hline
\end{tabular}

Gm: geometrical mean; Hb: haemoglobin; NS: not significant; n: number of participants.

TABLE 3: Geometric mean parasite density in the four categories of CD4 count.

\begin{tabular}{|c|c|c|c|c|c|c|c|c|}
\hline \multirow{2}{*}{$\begin{array}{l}\text { CD4 Category } \\
\left(/ \mathrm{mm}^{3}\right)\end{array}$} & \multirow{2}{*}{$\mathrm{N}$} & \multirow{2}{*}{$\begin{array}{c}\mathrm{Gm} \\
\text { Parasite density }\end{array}$} & \multirow{2}{*}{ S.D. } & \multirow{2}{*}{ Std. Error } & \multicolumn{2}{|c|}{$95 \%$ CI for mean } & \multirow{2}{*}{ Min } & \multirow{2}{*}{ Max } \\
\hline & & & & & Lower Bound & Upper Bound & & \\
\hline$<200$ & 15 & 4.254 & .7622 & .1968 & 3.832 & 4.676 & 3.0 & 5.3 \\
\hline $200-349$ & 24 & 4.499 & .5192 & .1060 & 4.279 & 4.718 & 3.7 & 5.3 \\
\hline $350-499$ & 24 & 4.332 & .5829 & .1190 & 4.085 & 4.578 & 3.2 & 5.3 \\
\hline$>500$ & 58 & 4.196 & .5372 & .0705 & 4.055 & 4.337 & 3.1 & 5.3 \\
\hline Total & 121 & 4.290 & .5789 & .0526 & 4.186 & 4.394 & 3.0 & 5.3 \\
\hline
\end{tabular}

The mean parasite density pretreatment was 43,168 parasites $/ \mu \mathrm{L}$ of blood and the median was 17,720 while the mode was 4,000 . The mean temperature on recruitment, prior to commencement of antimalarial therapy, was $37.6^{\circ} \mathrm{C}$ (slightly febrile), and median temperature was $37.4^{\circ} \mathrm{C}$ (normal), while the mode was $37.0^{\circ} \mathrm{C}$. Temperature range was $34.8^{\circ} \mathrm{C}-40.9^{\circ} \mathrm{C}$. The mean blood haemoglobin of participants was $11.7 \mathrm{~g} / \mathrm{dl}$ while median and mode were $11.9 \mathrm{~g} / \mathrm{dl}$ and $12.5 \mathrm{~g} / \mathrm{dl}$, respectively. Mean CD4 cells count was 519.3 with a median of 478 and the mode was 449 with a range of between 12 and 1567.

\subsection{Comparison of Geometrical Means of Parasite Density,} Temperature, $\mathrm{Hb}$, and Temperature within Gender Day 0. The mean age of the participants was 32.1 and 30.2 for females and males, respectively ( $p>0.524)$ (Table 2). Data revealed a higher geometrical mean parasite density for males $(26,424)$ than for females $(15,346)$ with a significant difference within gender $(\mathrm{p}<0.03)$. The mean haemoglobin for males was 12.4 , significantly different from that of females of $11.2(\mathrm{p}>0.04)$.

3.3. Mean Malaria Parasite Density in Different Age Groups Pretreatment at Day 0 . The ages below 5 years of age and those between 10 and 19 years had higher mean parasite density compared to the other age groups (Figure 2).
3.4. Malaria Parasite Density Relative to CD4 Cells Count Prior to Antimalarial Therapy. Participating individuals' CD4 values were analyzed against parasitaemia prior to commencement of antimalarial therapy on day 0 (Figure 3, Table 3, and Figure 4) and results showed a negative correlation between CD4 count and malaria parasite densities, but the correlation, however, was statistically insignificant ( $p$ $>0.169$ ). Data presented (Figure 3) seem to suggest that low CD4 counts was associated with high density malaria parasitaemia. Consequently, very high CD4 counts seemed to exhibit low malaria parasite density among people living with HIV/AIDS. The geometrical mean parasitaemia (Gm) in the four categories of CD4 count (Table 3) indicates that individuals with $<200 \mathrm{CD} 4$ cells $/ \mathrm{mm}^{3}$ had a higher SD and Std error than their counterparts whose CD4 counts were above $200 / \mathrm{mm}^{3}$. When $\mathrm{Hb}$ versus parasitaemia data were analyzed and correlated, the correlation, however, was not statistically significant, $\mathrm{p}=0.543$.

\section{Discussion}

It is apparent that association between the two infections (malaria and HIV) at the biological, immunological, and drug levels does exist. A significant variation in parasite density has further been observed among malaria/HIV coinfected groups [9]. Other studies indicate that HIV-1 positive individuals tend to have a significantly higher mean malaria 


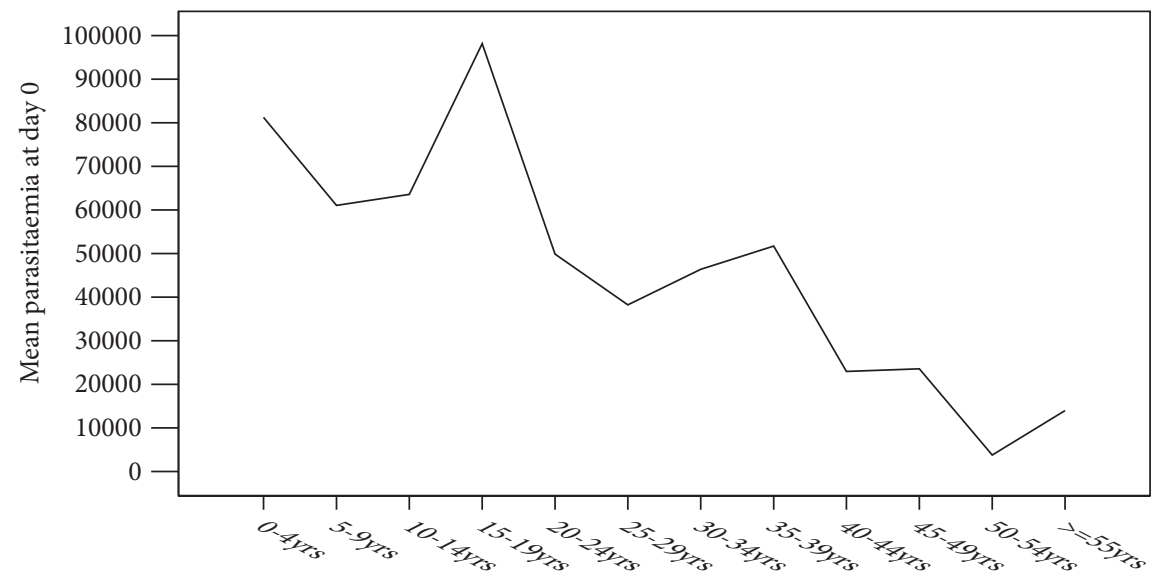

Age group

Figure 2: Mean parasite density in different age groups on day 0.

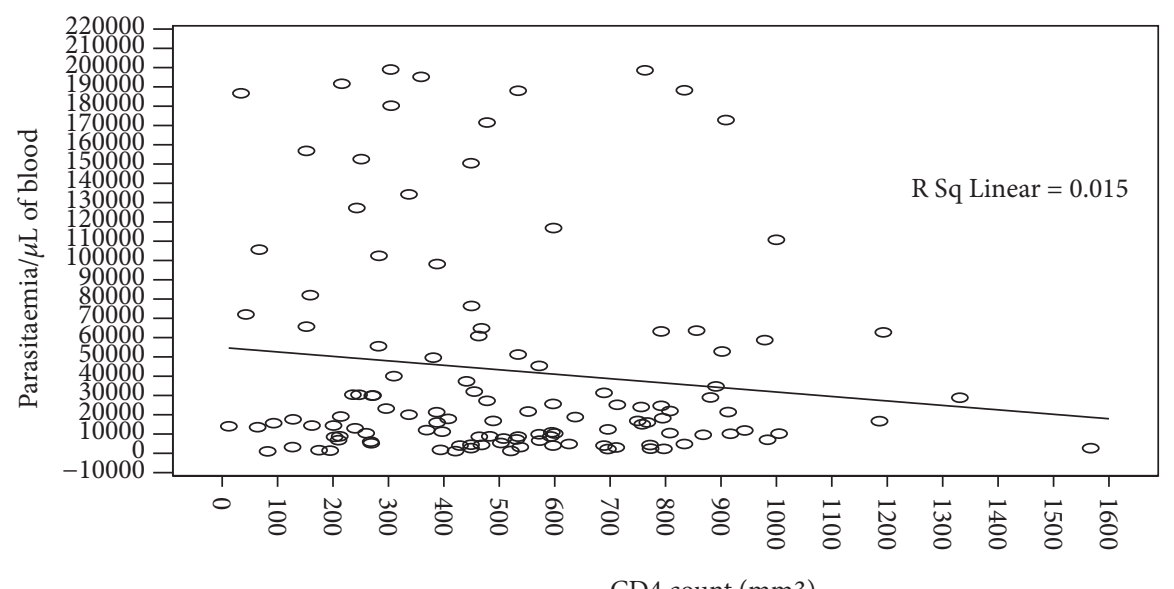

FIGURE 3: Density of malaria parasites relative to CD4 T-cells count on day 0.

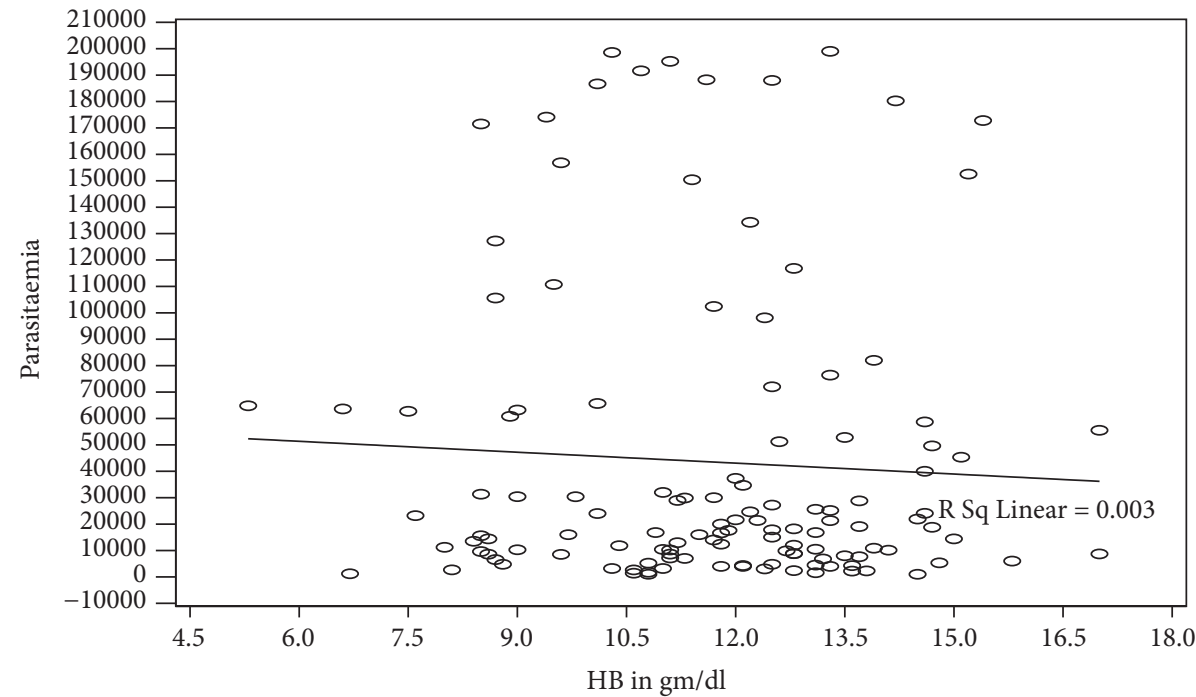

FIGURE 4: Haemoglobin and parasite density prior to antimalarial treatment. 
parasite density than their HIV-1 negative counterparts [16]. Triple infections of malaria, HIV/AIDS, and TB have been reported to increase malaria parasite densities, acid fast bacilli (AFB) count, and decreased haemoglobin levels among individuals in endemic areas [10]. These coinfections may worsen the immune response to either of the diseases [9]; cause transient increases in HIV-1 viral load that may progress to AIDS disease [17, 18]; and also predict an increased rate of AIDS-related disease (ARD) among PLWHA.

The current study findings showed that individuals living with HIV within age brackets below 5 years and those between 10 and 19 years had the highest malaria density of about $95,000 / \mu \mathrm{L}$ regardless of their CD4 T-cells status. The current results seem to resonate well with data obtained from General Hospital; Makarfi Kaduna, Nigeria, where children aged 5-15 years had a statistically significant higher parasitaemia density compared to other age groups [19]. And in Cameroon, West Africa, a geometric mean malaria parasite density (GMPD) among children aged 1-15 years was significantly higher in those presented with fever and moderate anaemia than their respective counterparts [20]. The higher malaria parasitaemia densities among children aged below 5 years and individuals aged between 10 and 19 years old in this study could be associated with immunological factors. Malaria infection has been associated with high viral load while HIV reputed to cause more clinical malaria. These factors, together with generally low immunity in children under 5 years, could explain the high parasitaemia levels witnessed in the 0-5 age group [21], which could have been the case in the current study. But in the Cameroon study, however, a significantly higher geometric mean parasite density among children whose CD4 T- cells $\geq 500$ cells $/ \mu \mathrm{L}(491.3, \mathrm{P}=0.003)$ than the values below was observed [20]. In areas of stable malaria, adolescents (1019 year age group) usually have higher risks of malaria parasitaemia because of immunological as well as hormonal factors that come into play during their development [22]. And among Gabonese women living with HIV, a higher median malaria parasitaemia was reported in individuals with a CD4 T-cell count below $200 / \mu \mathrm{L}(\mathrm{p}=0.03)$ [11]. There is a possibility that the observed differences in parasite density may be encountered due to geographical differences in study population and levels of malaria endemicity.

The added immune deficiency syndrome due to HIV depletion of CD4 T-cells may explain the high parasite density among people living with HIV/AIDS as indicated in the current study. The infection of HIV/AIDS has been known not only to induce depletion of CD4 T-cells but also to reduce $\mathrm{CD} 8 \mathrm{~T}$-cells causing downmodulation, reduction in T-cell subpopulation, and defective cell mediated immunity against any microbial infection [23, 24].

Further, this study also documented a general higher geometrical mean malaria parasite density in males than in females with a significant difference within gender $(p=0.03)$, which was comparable with data obtained from Kaduna State, Nigeria [19].

\section{Conclusions}

This study established a higher parasite density among individual PLWHA with CD4 T-cells below $200 / \mu \mathrm{L}$ than their counterparts with cells above $200 / \mu \mathrm{L}$ ) levels. Further, males significantly had a higher geometrical mean parasite density than females regardless of their CD4 status. It is anticipated that the results from this study could be used/applied in developing interventional measures to address malaria/HIVAIDS coinfections aimed at saving life, particularly in the subSaharan African region where the two infections are rampant.

\section{Data Availability}

The data used to support the findings of this study are available from the corresponding author upon request.

\section{Conflicts of Interest}

The author declares that there are no conflicts of interest with regard to publication of this article.

\section{Acknowledgments}

The author thanks and expresses a lot of gratitude to all individuals who reviewed and critiqued the manuscript and offered tangible and valuable suggestions to the draft of this article and all staffs of Chulaimbo Health Centre, Kisumu; Centre for Biotechnology Research and Development in KEMRI; the Division of Vector Borne Diseases (DVBD) at Kapsabet Hospital and DVBD Nairobi office for their cooperation and assistance. The author acknowledges the financial support provided by Moi University, through staff development kitty, for research that enabled the undertaking of this study.

\section{References}

[1] WHO, "Estimated number of malaria cases by WHO region, 2000-2015," World Malaria Report, World Health Organization, Geneva, Switzerland, 2016.

[2] CDC, Global Health, Division of Parasitic Diseases and Malaria, 2015.

[3] UNAIDS, "HIV epidemic and response estimates, global and by region, 2010 and 2015," Global AIDS Update, 2016.

[4] UNAIDS, Joint United Nations Programme on HIV/AIDS, 2017.

[5] National AIDS Control Council - (NACC), Kenya County Profile, 2014.

[6] R. González, R. Ataíde, D. Naniche, C. Menéndez, and A. Mayor, "HIV and malaria interactions: Where do we stand?" Expert Review of Anti-infective Therapy, vol. 10, no. 2, pp. 153$165,2012$.

[7] WHO, Malaria in HIV/AIDS Patients, 2017.

[8] C. Naing, N. K. Sandhu, and V. N. Wai, "The effect of malaria and HIV co-infection on anemia: a meta-analysis," Medicine, vol. 95, no. 14, pp. 14-23, 2016.

[9] H. Chavale, J. R. Santos-Oliveira, A. M. Da-Cruz, and S. Enosse, "Enhanced T cell activation in Plasmodium falciparum malaria-infected human immunodeficiency virus-1 patients 
from Mozambique," Memórias do Instituto Oswaldo Cruz, vol. 107, no. 8, pp. 985-992, 2012.

[10] A. A. Irene, M. A. Enekembe, H. D. Meriki et al., "The effect of malaria/HIV/TB triple infection on malaria parasitaemia, haemoglobin levels, CD4+ cell and acid fast bacilli counts in the South West Region of Cameroon," Journal of Infectious Pulmonary Diseases, vol. 2, no. 1, 2016.

[11] M. K. Bouyou Akotet, J. V. Koumba Lengongo, M. Ondounda et al., "Burden of asymptomatic malaria, anemia and relationship with cotrimoxazole use and CD4 cell count among HIV1infected adults living in Gabon, Central Africa," Pathogens and Global Health, vol. 112, no. 2, pp. 63-71, 2018.

[12] The Data Platform for the Horn of Africa (DEPHA) (http:// depha.org/).

[13] A. S. Asito, E. Piriou, W. G. Z. O. Jura et al., "Suppression of circulating IgD+CD27+ memory B cells in infants living in a malaria-endemic region of Kenya," Malaria Journal, vol. 10, pp. 362-370, 2011.

[14] G. M. Satti, S. H. Elhassan, and S. A. Ibrahim, "The efficacy of artemether versus quinine in the treatment of cerebral malaria," Journal of the Egyptian Society of Parasitology, vol. 32, no. 2, pp. 611-623, 2002.

[15] F. E. McKenzie, W. A. Prudhomme, A. J. Magill et al., "White blood cell counts and malaria," The Journal of Infectious Diseases, vol. 192, no. 2, pp. 323-330, 2005.

[16] E. K. Rutto, J. Nyagol, J. Oyugi et al., "Effects of HIV-1 infection on malaria parasitemia in milo sub-location, western Kenya," BMC Research Notes, vol. 8, no. 1, pp. 303-307, 2015.

[17] A. Alemu, Y. Shiferaw, Z. Addis, B. Mathewos, and W. Birhan, "Effect of malaria on HIV/AIDS transmission and progression," Parasites \& Vectors, vol. 6, no. 1, pp. 18-25, 2013.

[18] M. Iroezindu, E. Agaba, C. Daniyam et al., "Association of HIVinduced immuno-suppre-ssion \& clinical malaria in Nigerian adults," African Journal of Infectious Diseases, vol. 6, no. 2, pp. 48-53, 2012.

[19] M. L. Umaru and G. N. Uyaiabasi, "Prevalence of malaria in patients attending the general hospital Makarfi, Makarfi Kaduna - State, North-Western Nigeria," American Journal of Infectious Diseases and Microbiology, vol. 3, no. 1, pp. 1-5, 2015.

[20] A. Bate, H. K. Kimbi, E. Lum et al., "Malaria infection and anaemia in HIV-infected children in Mutengene, Southwest Cameroon: a cross sectional study," BMC Infectious Diseases, vol. 16, no. 1, pp. 523-531, 2016.

[21] S. C. K. Tay, K. Badu, A. A. Mensah, and S. Y. Gbedema, "The prevalence of malaria among HIV seropositive individuals and the impact of the co-infection on their hemoglobin levels," Annals of Clinical Microbiology and Antimicrobials, vol. 14, no. 1, pp. 10-17, 2015.

[22] D. G. Lalloo, P. Olukoya, and P. Olliaro, "Malaria in adolescence: burden of disease, consequences, and opportunities for intervention," The Lancet Infectious Diseases, vol. 6, no. 12, pp. 780793, 2006.

[23] Z. Iliyasu, M. Babashani, I. S. Abubakar, A. A. Salahudeen, and M. H. Aliyu, "Clinical burden and correlates of HIV and malaria co-infection, in northwest Nigeria," Acta Tropica, vol. 128, no. 3, pp. 630-635, 2013.

[24] C. Flateau, G. L. Loup, and G. Pialoux, "Consequences of HIV infection on malaria \&amp; thera-peutic implications: a systematic review," The Lancet Infectious Diseases, vol. 11, no. 7, pp. 541-556, 2011. 


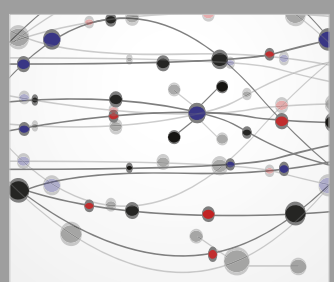

The Scientific World Journal
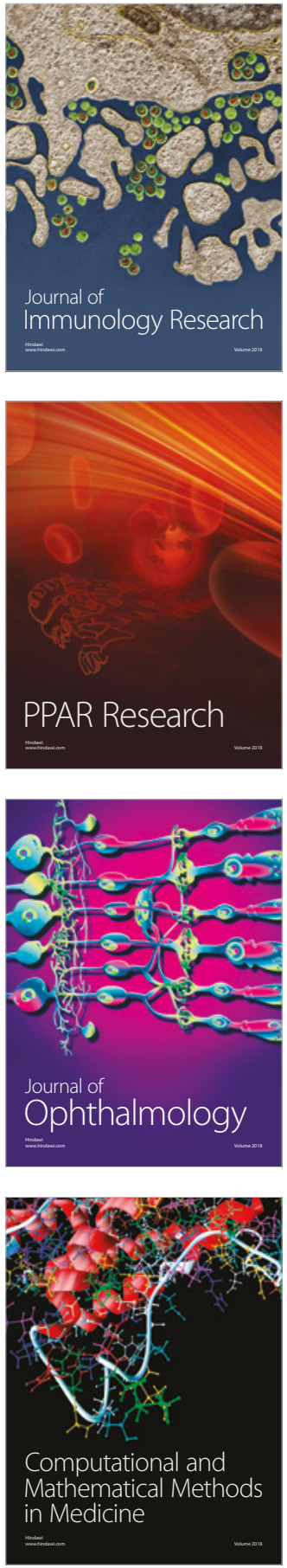

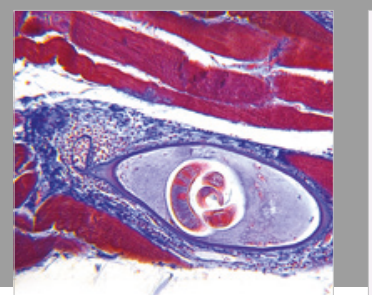

Gastroenterology Research and Practice

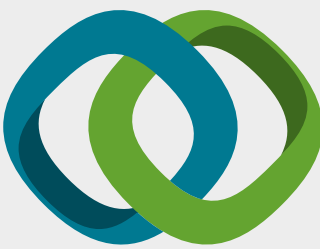

\section{Hindawi}

Submit your manuscripts at

www.hindawi.com
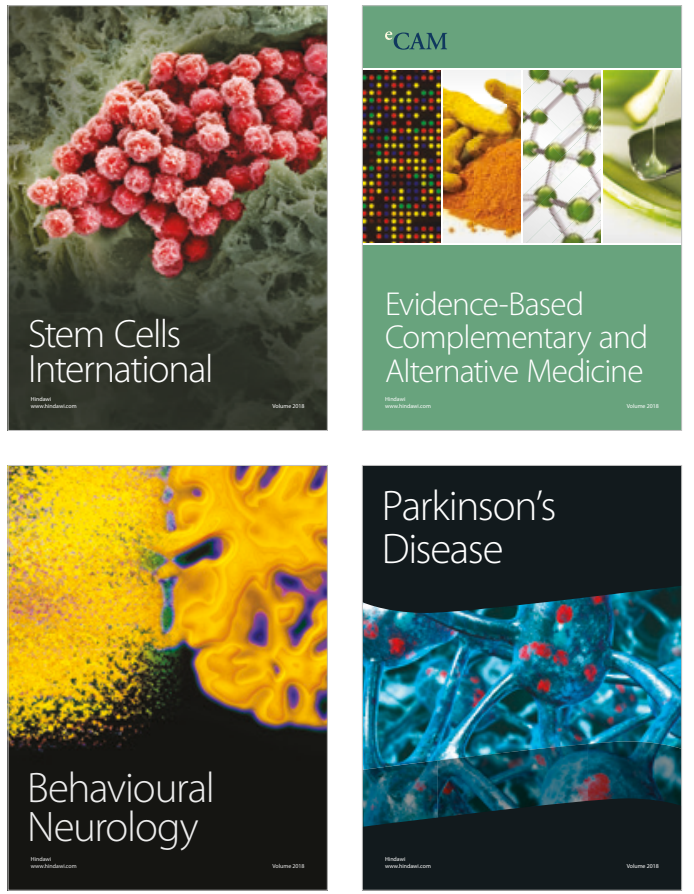

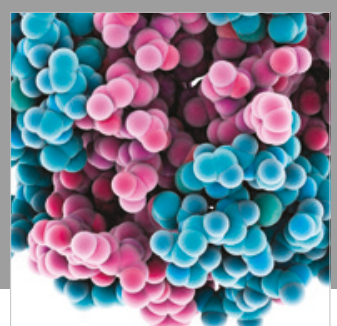

ournal of

Diabetes Research

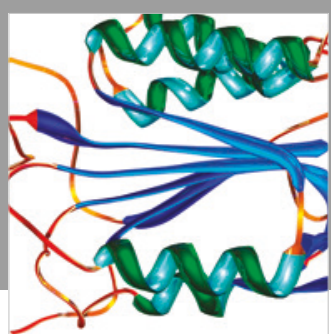

Disease Markers
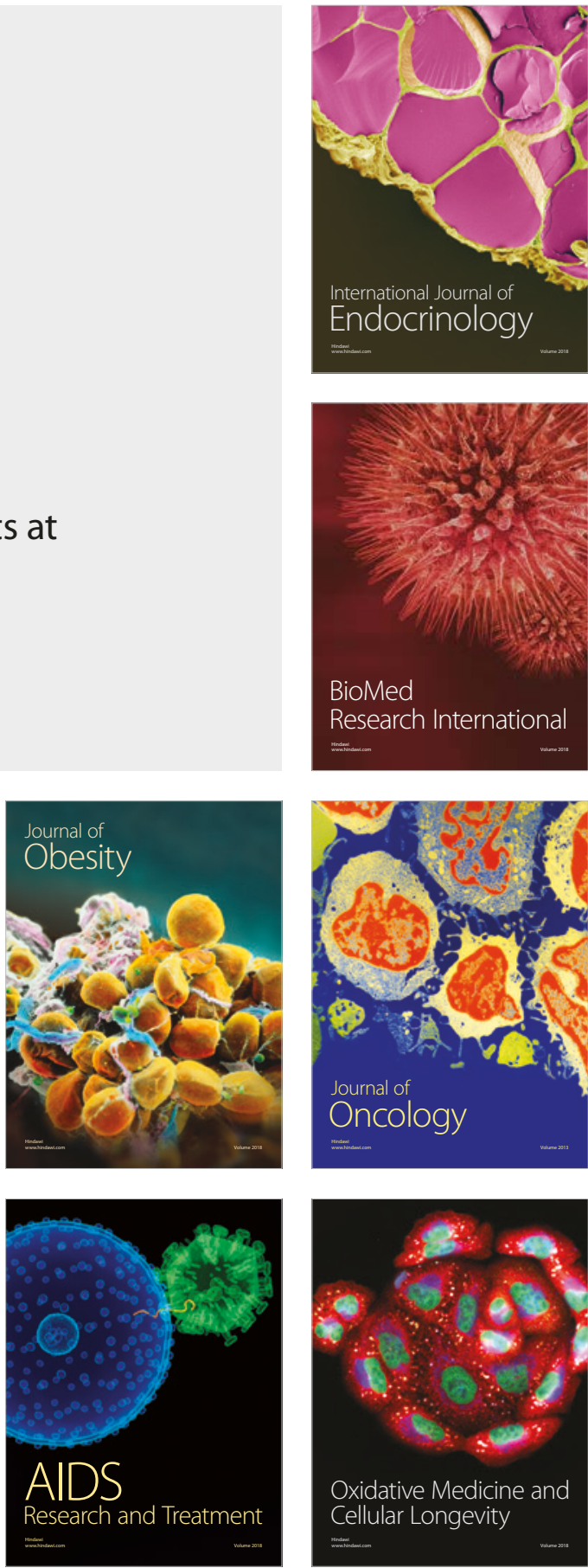